\title{
Correction to: An anatomical perspective on clinicopathological characteristics and treatment outcomes of dorsal and ventrolateral tongue leukoplakia after carbon dioxide laser surgery
}

Shih-Wei Yang ${ }^{1,2,3^{*}}$, Yun-Shien Lee ${ }^{4,5}$, Liang-Che Chang ${ }^{2,6}$, Cheng-Han Yang ${ }^{2,6}$ and Cheng-Ming Luo ${ }^{1,2}$

\section{Correction to: BMC Oral Health (2021) 21:45 https://doi.org/10.1186/s12903-021-01403 $-8$}

After publication of the original article [1], the authors identified an error in the Results section of the Abstract.

The incorrect sentence is: "Annual transformation rate was 4.03\%".

The correct sentence is: "Annual transformation rate was $1.08 \%$.

The original article has been corrected.

\section{Author details}

1 Department of Otolaryngology Head and Neck Surgery, Chang Gung Memo-

rial Hospital, Keelung. No. 222, Mai Chin Road, Keelung 204, Taiwan, ROC.

${ }^{2}$ College of Medicine, Chang Gung University, Taoyuan, Taiwan, ROC. ${ }^{3}$ New Taipei Municipal Tucheng Hospital, New Taipei City, Taiwan, ROC. ${ }^{4}$ Genomic Medicine Research Core Laboratory, Chang Gung Memorial Hospital,

Tao-Yuan, Taiwan, ROC. ${ }^{5}$ Department of Biotechnology, Ming Chuan University, Tao-Yuan, Taiwan, ROC. ${ }^{6}$ Department of Pathology, Chang Gung Memorial Hospital, Keelung, Taiwan, ROC.

Published online: 15 February 2021

The original article can be found online at https://doi.org/10.1186/s1290 3-021-01403-8.

\footnotetext{
*Correspondence: sweeyang@gmail.com

1 Department of Otolaryngology Head and Neck Surgery, Chang Gung

Memorial Hospital, Keelung. No. 222, Mai Chin Road, Keelung 204, Taiwan,

$\mathrm{ROC}$

Full list of author information is available at the end of the article
}

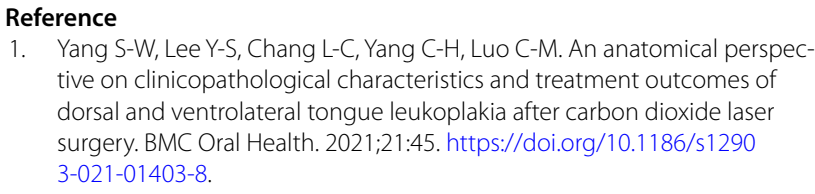

1. Yang S-W, Lee Y-S, Chang L-C, Yang C-H, Luo C-M. An anatomical perspective on clinicopathological characteristics and treatment outcomes of dorsal and ventrolateral tongue leukoplakia after carbon dioxide laser surgery. BMC Oral Health. 2021;21:45. https://doi.org/10.1186/s1290 3-021-01403-8.

\section{Publisher's Note}

Springer Nature remains neutral with regard to jurisdictional claims in published maps and institutional affiliations.

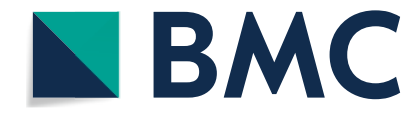

(O) The Author(s) 2021. Open Access This article is licensed under a Creative Commons Attribution 4.0 International License, which permits use, sharing, adaptation, distribution and reproduction in any medium or format, as long as you give appropriate credit to the original author(s) and the source, provide a link to the Creative Commons licence, and indicate if changes were made. The images or other third party material in this article are included in the article's Creative Commons licence, unless indicated otherwise in a credit line to the material. If material is not included in the article's Creative Commons licence and your intended use is not permitted by statutory regulation or exceeds the permitted use, you will need to obtain permission directly from the copyright holder. To view a copy of this licence, visit http://creativecommons.org/licenses/by/4.0/. The Creative Commons Public Domain Dedication waiver (http://creativeco mmons.org/publicdomain/zero/1.0/) applies to the data made available in this article, unless otherwise stated in a credit line to the data. 